\title{
Amino Acid (System A) Transporter Activity in Microvillous Membrane Vesicles from the Placentas of Appropriate and Small for Gestational Age Babies
}

DHUSHY MAHENDRAN, PAUL DONNAI, JOCELYN D. GLAZIER, STEPHEN W. DSOUZA, ROBERT D. H. BOYD. AND COLIN P. SIBLEY

Departments of Child Ilealth /D.M., J.D.G., S.W.D., R.D.H.B., C.P.S.J

Obstetric's and Ginateology/D.M., P.D.J. and Physiological Science's /C.P.S./. Action Rese'arch Placental and

Perinatal Research Unit, University of Manchester. St. Hary's Hospital, Manchester. MI13 OJH. United Kingdom

\begin{abstract}
Although a number of causes of poor fetal growth are known, the involvement of placental transport proteins in the etiology of growth retardation is not understood. The aim of this study was to investigate the activity of the system $A$ amino acid transporter and the $\mathrm{Na}^{+} / \mathrm{II}^{+}$ exchanger in vesicles isolated from the microvillous membrane of the syncytiotrophoblast of placentas of appropriate and small for gestational age babies. There were no biochemical differences between the membranes from the two groups of placentas, and there was no difference in the activity of the $\mathrm{Na}^{+} / \mathrm{H}^{+}$exchanger. The initial rate of uptake of methylaminoisobutyric acid (a nonmetabolizable amino acid analogue) was $63 \%$ lower in vesicles from placentas of small for gestational age babies. Kinetic analysis of the system $A$ transporter (utilized by methylaminoisobutyric acid) showed that the $V_{\max }$ in the vesicles from placentas of small for gestational age babies $(0.24 \pm 0.03 \mathrm{nmol} / \mathrm{mg}$ protein/30 $\mathrm{s}, n=5$ ) was significantly lower than that in vesicles from placentas of appropriate for gestational age babies $(0.64 \pm 0.09 \mathrm{nmol} / \mathrm{mg}$ protein/30 s, $n=4, p<$ 0.001 ), whereas the $\mathrm{Km}$ was not different between the two groups. It is concluded that there is an abnormality of system $A$ amino acid transporter function in placentas of small for gestational age babies. (Pediatr Res 34: 661-665, 1993)
\end{abstract}

\section{Abbreviations}

AIB, aminoisobutyric acid

MeAIB, methylaminoisobutyric acid

SGA, small for gestational age

AGA, appropriate for gestational age

HEPES, $N$-2-hydroxyethylpiperazine- $N^{\prime}$-2-ethanesulfonic acid

Intrauterine growth retardation is of considerable importance, being associated with perinatal death (1), neonatal complications (2), and a high incidence of neurodevelopmental delay in survivors $(3,4)$. Furthermore, hypertension and its sequelae in later adult life are associated with low birth weight, especially in the presence of a large placenta (5).

Received January 6, 1993: accepted June 22, 1993

Correspondence: Dr. Colin P. Sibley, Dept. of Child Health. St. Mary`s I lospital, Manchester, M13 0JH, UK.

Supported by the North Western Regional Health Authority.
There are multiple determinants of intrauterine growth (4), including maternal size and nutrition, environmental agents ( $c . g$. cigarette smoking), and the health of the fetus and its genome together with, perhaps, the placenta's capacity to transport nutrients, which is the focus of the present study.

Experimental generalized diminution of placental mass causes growth retardation in a number of species (6-8), but it is not clear whether specific disorders of placental transport of individual solutes are related to growth retardation. Placental handling of amino acids is of interest in this regard because these substrates are essential for the production of protein and thus body mass in the developing fetus. There is also accumulating evidence that there may be abnormalities of transplacental transport of amino acids in the presence of poor fetal growth. Thus, in humans, $\alpha$ amino-nitrogen concentrations in umbilical vein plasma obtained at cordocentesis are lower in the growth-retarded fetus than in the appropriately grown fetus $(9,10)$. In addition, dietary restriction in rats $(11,12)$ and vascular manipulations in rats $(7)$ and guinea pigs (8) used to cause fetal growth retardation result in decreased net placental transfer of the nonmetabolizable amino acid analogue AIB to the fetus.

Direct evidence that placental amino acid transport is defective in human growth retardation came from a study in which AIB uptake into vesicles prepared from the microvillous (maternal facing) membrane of the placental syncytiotrophoblast was found to be lower in those from SGA pregnancies than those from AGA pregnancies (13). However, this study did not address whether the defect was specific to one transport system or rather reflected a generalized difference between the placentas of the two groups or in the vesicles prepared from them.

Although existing data imply that placental transport may be defective in the presence of growth retardation, it remains to be established whether this is causative in fetal growth retardation. A defect in a specific transport system might be either a causal event in poor growth or a response to poor growth itself. Nevertheless, identification of a specific defect would provide an important step forward in unraveling causality and was the aim of the present project.

We therefore characterized microvillous membrane vesicles prepared from placentas of growth-retarded and normally grown babies so as to exclude the possibility of any systematic preparative differences. We then measured the activity of the $\mathrm{Na}^{+}$dependent system A amino acid transporter, determined by measuring the uptake of MeAIB [a nonmetabolizable amino acid analogue (14)] and that of the $\mathrm{Na}^{+} / \mathrm{H}^{+}$exchanger (15), as an example of a transporter not directly involved in amino acid fluxes, in both sets of vesicles. 


\section{MATERIALS AND METHODS}

Patients and collection of placentas. All patients were Caucasians followed antenatally and delivered at St. Mary's Hospital. Vesicles were studied from a total of 21 placentas (AGA vesicles) from pregnancies in which the birth weight of the baby was between the 10th and 90th percentiles (16), and of these 21 sets of vesicles, 18 had uptake experiments performed on them. Fourteen placentas from SGA babies in which the birth weight was less than the 3 rd percentile (16) were also studied (SGA vesicles). Gestational age was estimated from the first day of the last menstrual period, and ultrasound scan assessment of gestation was done at $16 \mathrm{wk}$ of gestation. If there was more than I wk difference in the gestational age assessed by these two techniques, the tissue was excluded. All placentas were from pregnancies at term $(\mathrm{AGA}=39.4 \pm 0.4 \mathrm{wk}$ and $\mathrm{SGA}=39.0 \pm 0.3$ wk, mean \pm SEM). All the babies were normal on clinical examination. There was no maternal disease or obvious fetal abnormality in any of the patients. Study and control subjects were not significantly different (using Fisher's exact test) in maternal age $(\mathrm{AGA}=29.5 \pm 1.5 \mathrm{y}, \mathrm{SGA}=25.9 \pm 1.4 \mathrm{y}$, mean $\pm \mathrm{SEM})$, parity $(\mathrm{AGA}=1.0 \pm 0.2, \mathrm{SGA}=0.7 \pm 0.2)$, maternal smoking habit (five mothers in the AGA group; seven mothers in the SGA group), or mode of delivery (15 vaginal, five cesarean section, one forceps delivery in the AGA group; eight vaginal, five cesarean section, one forceps delivery in the SGA group).

Preparation of microvillous membrane vesicles. Microvillous membrane isolation was commenced as soon as possible after delivery, but always within $30 \mathrm{~min}$. The chorionic plate was excised and a portion of the placenta (approximately $100 \mathrm{~g}$ ) was homogenized, followed by $\mathrm{Mg}^{2+}$ precipitation and differential centrifugation (17). The resulting pellet of microvillous membrane was suspended in the appropriate buffer and repeatedly drawn through a 25 -gauge needle to vesiculate the membrane fragments (17).

Protein content of the homogenate and of vesicles from each placenta was assayed (18). Alkaline phosphatase activity (a marker of the microvillous membrane) was measured according to the method of McComb and Bowers (19). NADH dehydrogenase (a marker of endoplasmic reticulum, 20) and succinate dehydrogenase (a marker of mitochondria, 21) were also measured. An enrichment ratio, defined as activity in the vesicle suspension relative to that in the initial placental homogenate, was calculated for the markers. Vesicle orientation was established by calculating the change in alkaline phosphatase activity after vesicle disruption with $0.1 \%$ saponin (17).

Microvillous membrane vesicles were stored at $4^{\circ} \mathrm{C}$ before use, and all uptakes were performed within $48 \mathrm{~h}$ of their isolation. Some preparations were used to measure uptake of $\mathrm{Na}^{+}$and MeAIB, and others were used to measure uptake of one of these substrates only.

$\mathrm{Na}^{+}$uptake. Sodium uptake into vesicles was performed at room temperature as previously described (17). The vesicles were reconstituted in $25 \mathrm{mM} 2$ [N-morpholino]cthanesulfonic acid, 5 $\mathrm{mM}$ Tris, $149 \mathrm{mM} \mathrm{KCl}$, and $1 \mathrm{mM} \mathrm{NaCl}, \mathrm{pH} \mathrm{5.6}$. Uptake of ${ }^{22} \mathrm{Na}^{+}$was then initiated by the addition of $900 \mu \mathrm{L}$ of extravesicular buffer (18 mM HEPES, $12 \mathrm{mM}$ Tris, $149 \mathrm{mM} \mathrm{KCl}, 1 \mathrm{mM}$ $\mathrm{NaCl}, 2.5 \mu \mathrm{Ci} / \mathrm{mL}^{22} \mathrm{Na}^{+}$, pH 7.6) with and without $0.5 \mathrm{mM}$ amiloride [an inhibitor of the $\mathrm{Na}^{+} / \mathrm{H}^{+}$exchanger at this concentration (22)] to $200 \mu \mathrm{L}$ (2-4 mg of protein) of vesicles suspension. Thus, $\mathrm{Na}^{+}$uptake into the vesicles was studied in the presence of an outwardly directed proton gradient. The difference between proton gradient-stimulated ${ }^{22} \mathrm{Na}^{+}$uptake in the presence and absence of amiloride gives a measure of $\mathrm{Na}^{+} / \mathrm{H}^{+}$exchanger activity $(15,17)$. At timed intervals, $100-\mu \mathrm{L}$ aliquots were removed and applied to an ion exchange column (23) to separate extravesicular from intravesicular ${ }^{22} \mathrm{Na}^{+}$and washed with cold $\left(4^{\circ} \mathrm{C}\right.$ ) extravesicular buffer (minus the ${ }^{22} \mathrm{Na}^{+}$). The eluents from the columns (containing vesicles and their associated ${ }^{22} \mathrm{Na}^{+}$) were counted in a Packard $800 \mathrm{C}$ gamma counter (Packard Instrument
Co., Downers Grove, IL). Counts associated with vesicles were corrected for radiolabel not retained by the columns in the absence of vesicle protein. Nonspecific binding of radiolabel, as opposed to uptake, to the membrane was established by incubating in the presence of $0.2 \%$ triton to cleave the vesicles. The proportion of vesicle protein retained by the Dowex columns was measured by assaying the eluent for alkaline phosphatase and comparing this with the amount applied to the top of the column.

MeAIB uptake. The MeAIB uptake was measured as previously described (14) in the presence and absence of an inwardly directed $\mathrm{Na}^{+}$gradient into the vesicles. The $\mathrm{Na}^{+}$-dependent component of MeAIB transport (reflecting the $\mathrm{Na}^{+}$-dependent system $A$ transporter) was taken as the difference in uptake under the two sets of conditions. The vesicles were suspended in $5 \mathrm{mM}$ HEPES, $5 \mathrm{mM}$ Tris- $\mathrm{HCl}, 290 \mathrm{mM}$ sucrose (pH 7.4), and uptake was initiated by the addition of $20 \mu \mathrm{L}$ of vesicles (approximately $150 \mu \mathrm{g}$ of protein) to $20 \mu \mathrm{L}$ of extravesicular buffer $(5 \mathrm{mM}$ HEPES, $5 \mathrm{mM}$ Tris, $145 \mathrm{mM} \mathrm{NaCl}$ or $145 \mathrm{mM} \mathrm{KCl}, 0.165 \mathrm{mM}$ ${ }^{14} \mathrm{C}-\mathrm{MeAIB}, \mathrm{pH}$ 7.4). At timed intervals, vesicular uptake of MeAIB was stopped by the addition of $2 \mathrm{~mL}$ of ice cold Krebs Ringer phosphate buffer (KRP; $130 \mathrm{mM} \mathrm{NaCl}, 10 \mathrm{mM}$ $\mathrm{Na}_{2} \mathrm{HPO}_{4}, 4.2 \mathrm{mM} \mathrm{KCl}, 1.2 \mathrm{mM} \mathrm{MgSO}$, and $0.75 \mathrm{mM} \mathrm{CaCl}_{2}$, $\mathrm{pH}$ 7.4), and $1 \mathrm{~mL}$ of the resulting solution was promptly removed and applied to a $0.45-\mu \mathrm{m}$ Millipore filter, which had been presoaked in ice cold KRP, followed by washing with 10 $\mathrm{mL}$ of cold KRP. Membrane binding was quantified by incubating vesicles in the presence of $0.2 \%$ triton. Counts were corrected for radiolabel retained by the filters in the absence of vesicle protein. The Millipore filters were dissolved in $2 \mathrm{~mL}$ of $2-$ ethoxyethanol, and counted in a Packard 2000CA liquid scintillation analyzer after addition of $12 \mathrm{~mL}$ of Optiphase 'HiSafe' II scintillation fluid (Pharmacia, Milton Keynes, UK).

To study its kinetics, $\mathrm{Na}^{+}$-dependent ${ }^{14} \mathrm{C}$-MeAIB uptake at 30 $\mathrm{s}$ (taken to be initial rate; see Results) was measured as described above in the presence of a range of concentrations of MeAIB. Uptake was plotted against MeAIB concentration, the data were fitted to the Michaelis Menten equation by nonlinear regression (P-Fit, Biosoft, Cambridge, UK), and $\vec{V}_{\max }$ and $\mathrm{Km}$ of the transporter were calculated.

Radioisotopes were obtained from either Amersham (Aylesbury, Bucks, UK) or New England Nuclear (Stevenage, Herts, UK), and chemicals from Sigma Chemicals (Poole, Dorset, UK) or BDH (Liverpool, UK).

Statistics. All data are shown as mean \pm SEM, and $n$ is the number of pregnancies studied. Statistical analysis was by paired or unpaired $t$ test or Fisher's exact test, as appropriate, with $p<$ 0.05 taken to be significant.

Ethical approval. Ethical approval was obtained from the Central Manchester Health Authority Ethical Committee.

\section{RESULTS}

As expected, there was a significantly $(p<0.0001)$ lower birth weight in the SGA group $(2.21 \pm 0.06 \mathrm{~kg}, n=14)$ compared with the AGA group of babies $(3.38 \pm 0.07 \mathrm{~kg}, n=18)$. Mean placental weights were also significantly $(p<0.0001)$ lower in the SGA group compared with the AGA group (443 \pm 27 and $629 \pm 29$ g, respectively).

Membrane purity. Alkaline phosphatase was enriched in both the SGA and AGA vesicles, and there was no statistical difference between the two groups (Table 1). The other markers showed no enrichment in the vesicles. There was no difference, at the $5 \%$ level of significance, in the protein recovery in the SGA and AGA vesicles. Vesicle orientation was also not different between the two groups and suggested that the vesicles were "right side out" i.e. the in rivo extracellular facing domain was on the outside.

Mean protein recovery was lower in the SGA vesicles compared with AGA vesicles, but the difference was not statistically 
Table 1. Protein recovery; membrane marker enrichment ratios, and vesicle orientation (mean $\pm S E M$ ) in $S G A$ and $A G A$ vesicles

\begin{tabular}{lcc}
\hline & AGA & SGA \\
\hline Protein recovery $(\mathrm{mg} / \mathrm{g}$ & $0.43 \pm 0.06$ & $0.27 \pm 0.03$ \\
placenta) & $(n=18)$ & $(n=14)$ \\
Alkaline phosphatase enrich- & $22.4 \pm 2.2^{*}$ & $\left(19.1 \pm 1.6^{*}\right.$ \\
ment & $(n=18)$ & $(n=14)$ \\
Succinate dehydrogenase & $0.13 \pm 0.1$ & $0.01 \pm 0.005$ \\
enrichment & $(n=5)$ & $(n=5)$ \\
NADH dehydrogenase & $0.43 \pm 0.2$ & $0.16 \pm 0.05$ \\
enrichment & $(n=5)$ & $(n=5)$ \\
Vesicle orientation (\% right & $97.9 \pm 1.1$ & $99.0 \pm 2.1$ \\
side out) & $(n=9)$ & $(n=6)$ \\
\hline
\end{tabular}

* Significantly greater than unity ( $t$ test).

significant $(p=0.08)$ and was corrected for by normalizing uptake to vesicle protein concentration.

$\mathrm{Na}^{+}$uptake. Equilibrium uptake of ${ }^{22} \mathrm{Na}^{+}$in the presence of $0.2 \%$ triton, taken as reflecting binding to the membrane, was less than $4 \%$ in both AGA and SGA vesicles, implying that the majority of the $\mathrm{Na}^{+}$was entering an intravesicular space. Alkaline phosphatase activity in the eluent from the ion exchange columns compared with activity in that applied to the top of the column was not different between the two groups of vesicles $(62.9 \pm$ $4.5 \%, n=5$, and $68.6 \pm 6.5 \%, n=7$, in AGA and SGA groups, respectively), and therefore calculated uptakes were not corrected for recovery.

The uptake of ${ }^{22} \mathrm{Na}^{+}$in the presence of amiloride in placentas of AGA babies was significantly $(p<0.05)$ lower than in its absence at all time points up to and including $120 \mathrm{~min}$ (Fig. 1 1 ).

In paired experiments, uptake in the absence of amiloride, i.e. total $\mathrm{Na}^{+}$uptake, at $120 \mathrm{~min}(2.13 \pm 0.05 \mathrm{nmol} / \mathrm{mg}$ protein, $n$ $=3)$ was not different from that at $24 \mathrm{~h}(2.01 \pm 0.05 \mathrm{nmol} / \mathrm{mg}$ protein, $n=3$ ). Therefore, ${ }^{22} \mathrm{Na}^{+}$uptake at $120 \mathrm{~min}$ was taken to be at equilibrium.

The ${ }^{22} \mathrm{Na}^{+}$uptake into vesicles from SGA babies (Fig. $1 B$ ) was significantly $(p<0.05)$ lower in the presence of amiloride than in its absence up to and including $120 \mathrm{~min}$. There was no difference by $24 \mathrm{~h}$, suggesting that they had reached the same equilibrium. In paired experiments, the total $\mathrm{Na}^{+}$uptake, i.e. in the absence of amiloride, was not different between that at 120 $\min (1.91 \pm 0.16 \mathrm{nmol} / \mathrm{mg}$ protein, $n=4)$ and that at $24 \mathrm{~h}(1.46$ $\pm 0.28 \mathrm{nmol} / \mathrm{mg}$ protein, $n=4)$. There was no difference in the AGA and SGA vesicles with respect to equilibrium uptake, showing that the two groups did not differ in terms of vesicle volume (calculated as $2.54 \pm 0.21 \mu \mathrm{L} / \mathrm{mg}$ protein for $A G A$ and $2.50 \pm 0.25 \mu \mathrm{L} / \mathrm{mg}$ protein for SGA vesicles). There was no significant difference in total $\mathrm{Na}^{+}$or amiloride-insensitive or amiloride-sensitive $\mathrm{Na}^{+}$uptake between $\mathrm{AGA}$ and SGA vesicles at any time point up to and including $24 \mathrm{~h}$. Amiloride-sensitive $\mathrm{Na}^{+}$uptake (i.e. difference in uptake in the presence and absence of amiloride) was linear up to $1 \mathrm{~min}$ in both sets of vesicles, and uptake at $30 \mathrm{~s}$ was therefore used to calculate the initial rate of $\mathrm{Na}^{+}$transport due to the $\mathrm{Na}^{+} / \mathrm{H}^{+}$exchanger; there was no significant difference between the two groups of vesicles (Table 2).

MeAIB uptake. Vesicle uptake of ${ }^{14} \mathrm{C}-\mathrm{MeAIB}$ in the presence of $0.2 \%$ triton was less than $3 \%$ of total uptake at $120 \mathrm{~min}$ in vesicles from placentas of both the AGA and SGA babies (Figs. $2 A$ and $B$ ).

The time course of MeAIB uptake into AGA vesicles is shown in Figure $2 A$. In the presence of an $\mathrm{Na}^{+}$gradient into the vesicles, there was a significantly $(p<0.05)$ greater uptake of MeAIB compared with that in the presence of a $\mathrm{K}^{+}$gradient. By 120 min, there was no longer a significant difference between the two.

In the SGA vesicles, the uptake of ${ }^{14} \mathrm{C}-\mathrm{MeAIB}$ was again significantly $(p<0.05)$ greater in the presence of an $\mathrm{Na}^{+}$gradient
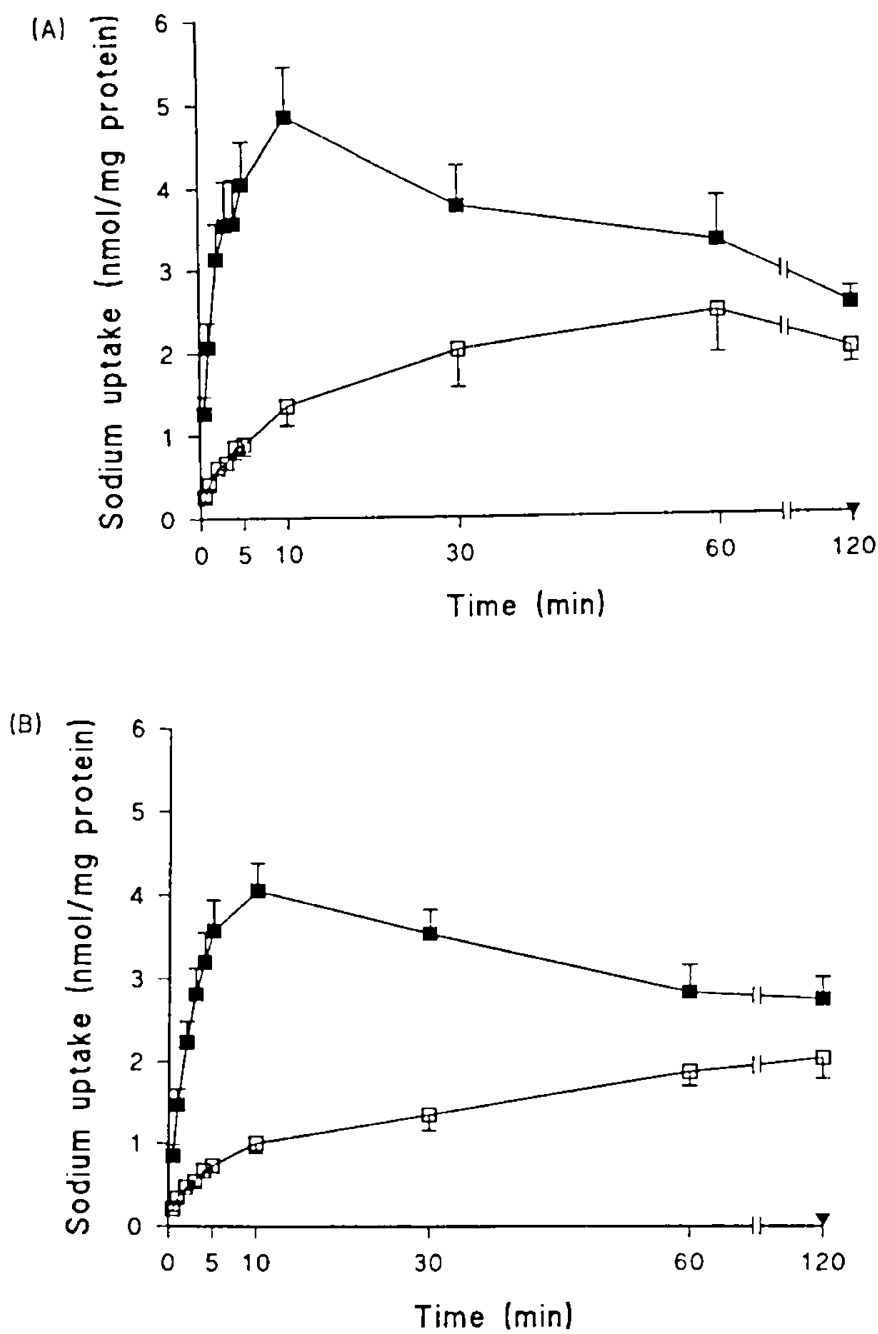

Fig. 1. Time course of uptake of $\mathrm{Na}^{+}$(expressed in $\mathrm{nmol} / \mathrm{mg}$ vesicle protein) into vesicles from placentas of $\mathrm{AGA}(.1)$ and SGA $(B)$ babies. The uptake in the absence ( $\square$ ) and presence of $0.5 \mathrm{mM}$ amiloride ( $\square$ ) and in the presence of $0.2 \%$ triton $(\nabla)$ are shown. Mean \pm SEM is shown except where error bars fall within the symbols. $n=6$ or 7 for the AGA group and $n=7$ or 9 for the SGA group. Not all time points were performed on each vesicle preparation.

Table 2. Initial rates of amiloride-sensitive $\mathrm{Na}^{+}$uptake and $\mathrm{Na}^{+}$-dependent MeAIB transport into vesicles from placentas of $A G A$ and SGA babies at $30 \mathrm{~s}$ (mean \pm SEMI)

\begin{tabular}{ccc}
\hline & AGA & SGA \\
\hline Amiloride sensitive Na ${ }^{+}$up- & $0.88 \pm 0.13$ & $0.57 \pm 0.10$ \\
take (nmol/mg protein) & $(n=10)$ & $(n=11)$ \\
$\mathrm{Na}^{+}$-dependent MeAlB up- & $0.038 \pm 0.005$ & $0.014 \pm 0.002^{*}$ \\
take (nmol/mg protein) & $(n=13)$ & $(n=10)$ \\
\hline
\end{tabular}

${ }^{*} p<0.001$ is AGA vesicles $(t$ test $)$.

into the vesicles than in the presence of a $\mathrm{K}^{+}$gradient throughout the time course shown in Figure $2 B$. However, by $24 \mathrm{~h}$ there was no such difference. Total MeAIB uptake (in the presence of an $\mathrm{Na}^{+}$gradient) was significantly lower in SGA vesicles at all time points up to and including 120 min compared with that in AGA vesicles, although by $24 \mathrm{~h}$ (equilibrium) there was no difference.

In both groups of vesicles, $\mathrm{Na}^{+}$-dependent MeAIB uptake was linear up to $1 \mathrm{~min}$ and uptake at $30 \mathrm{~s}$ was taken to be the initial rate of uptake via the system $A$ amino acid transporter. It was $63 \%$ lower in the SGA vesicles compared with the AGA vesicles (Table 2). The $\mathrm{Na}^{+}$-independent MeAIB uptake (i.e. that in the presence of a $\mathrm{K}^{+}$gradient) was also lower at $30 \mathrm{~s}$ in $\mathrm{SGA}$ vesicles 


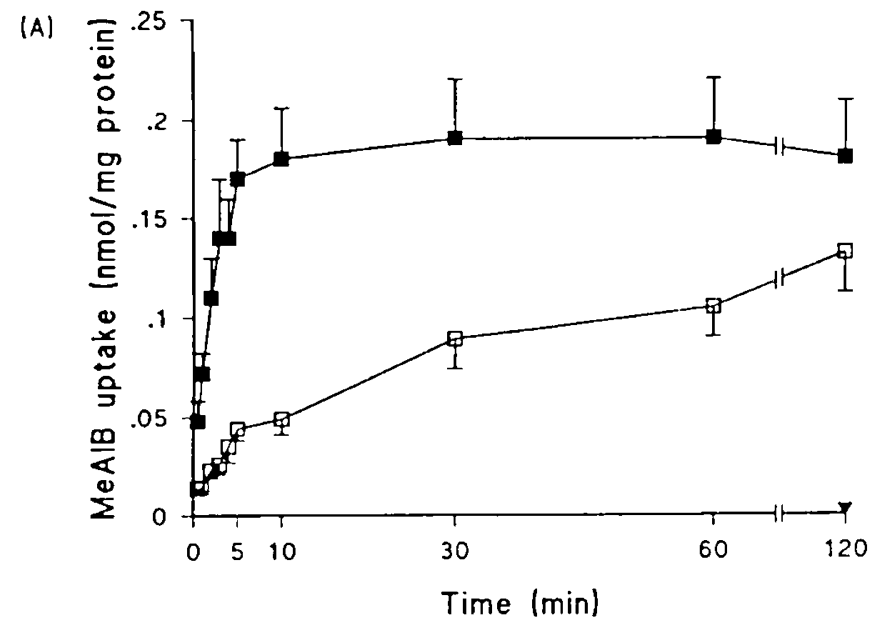

(B)

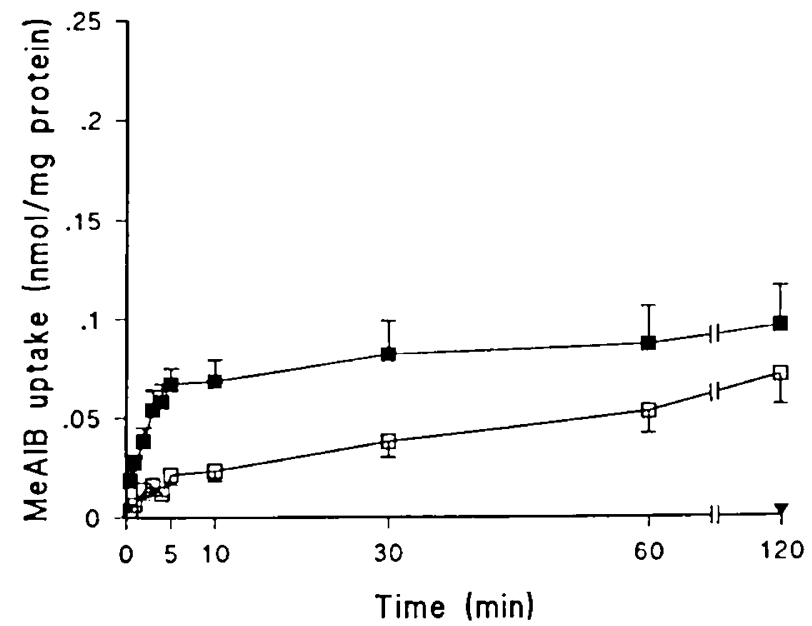

Fig. 2. Time course of uptake of MeAIB (expressed in $\mathrm{nmol} / \mathrm{mg}$ vesicle protein) into AGA $(A)$ and SGA $(B)$ vesicles. Uptakes in the presence of an $\mathrm{Na}^{+}$gradient $(\square)$ and a $\mathrm{K}^{+}$gradient $(\square)$ and in the presence of $0.2 \%$ triton $(\nabla)$ are shown. Mean \pm SEM is shown except where error bars fall within the symbol. $n=5$ or 6 for the AGA group and $n=4$ or 5 for the SGA group. Not all time points were performed on each vesicle preparation.

$(0.0051 \pm 0.0008 \mathrm{nmol} / \mathrm{mg}$ protein, $n=10)$ than in vesicles from AGA babies $(0.011 \pm 0.002 \mathrm{nmol} / \mathrm{mg}$ protein, $n=13, p<$ 0.05 ).

The initial $(30 \mathrm{~s}) \mathrm{Na}^{+}$-dependent uptake of MeAIB in AGA and SGA vesicles at various external concentrations of MeAIB is shown in Figure 3. The $\mathrm{Km}$ for AGA vesicles $(5.35 \pm 1.61$ $\mathrm{mM}, n=4$ ) was not significantly different (at the $5 \%$ level) from that in SGA vesicles $(2.10 \pm 0.83 \mathrm{mM}, n=5, p=0.09)$. However, $\mathrm{V}_{\max }$ was significantly lower in the SGA vesicles $(0.24 \pm 0.03$ $\mathrm{nmol} / \mathrm{mg}$ protein $/ 30 \mathrm{~s}, n=5)$ than in $A G A$ vesicles $(0.64 \pm 0.09$ $\mathrm{nmol} / \mathrm{mg}$ protein $/ 30 \mathrm{~s}, n=4, p<0.001$ ).

\section{DISCUSSION}

Transcellular transport of an amino acid across the placenta requires that it crosses both the microvillous plasma membrane (maternal facing) and basal plasma membrane (fetal facing) of the syncytiotrophoblast. It is uncertain which, if either, of these two steps is rate limiting in net transport of amino acids to the fetus. A number of transport systems for neutral amino acids have been reported in the human placenta as characterized by the classification of Christensen (24). System A in the microvillous membrane (14) transports alanine, glycine, proline, and

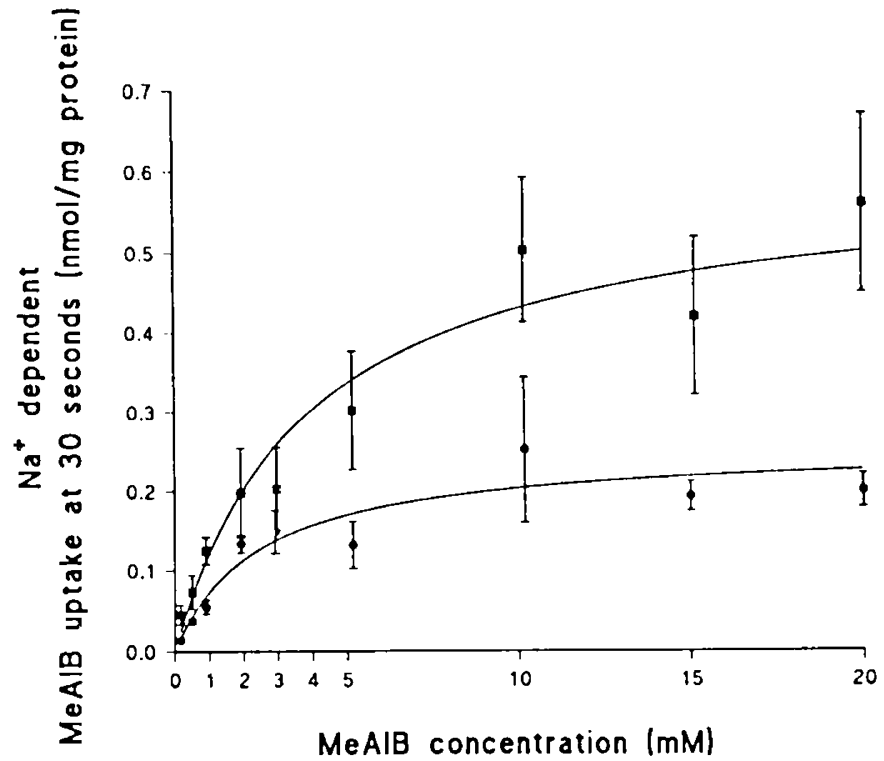

Fig. 3. Concentration dependence of initial $\mathrm{Na}^{+}$-dependent MeAIB uptake into AGA (D) and SGA (-) vesicles. Mean \pm SEM is shown except where the error bars fall within the symbols. $n=4$ for $A G A$ and $n=5$ for SGA vesicles.

threonine, as well as MeAIB. System $\mathrm{L}$, which is $\mathrm{Na}^{+}$independent, is found in the microvillous (14) and basal membranes (25). It preferentially transports leucine, isoleucine, valine, phenylalanine, threonine, and alanine. System ASC, which is $\mathrm{Na}^{+}$dependent, transports alanine, serine, and glutamine, and is present in the basal membrane of the syncytiotrophoblast $(25,26)$, but may not be in the microvillous membrane (14). There is also a $\beta$ system for taurine in the microvillous membrane (27), system $\mathrm{N}$ for histidine in the microvillous membrane (28), and system $\mathrm{T}$ for tyrosine in both microvillous and basal membranes (29). In this study, we have focused on whether there is a specific alteration in the activity of the system $A$ transporter in the microvillous membrane of placentas from women who gave birth to severely growth-retarded fetuses and in whom there was no obvious maternal or other fetal disease.

We found that there were no significant differences between the AGA and SGA microvillous membrane vesicles with respect to purity, protein recovery, vesicle orientation, or vesicle volume (as determined by equilibrium ${ }^{22} \mathrm{Na}^{+}$uptake), suggesting that there were no gross general or systematic preparative differences between the two groups. By contrast, system A transporter activity was markedly (63\%) lower in SGA than in AGA vesicles. The $\mathrm{Km}$ and $\mathrm{V}_{\max }$ for the transporter found in the present study are different from those previously described (14), but this may reflect differences in the isolation procedure and/or storage conditions $(17,30)$. Nevertheless $V_{\max }$, but not $\mathrm{Km}$ of the system $A$ transporter was significantly lower in the SGA compared with the AGA vesicles. This difference implies that either the turnover of the system A transporter was reduced in the microvillous membranes in the placentas of SGA babies or the number of active carrier proteins was reduced, but the affinity of the transporters was not different. An alternative possibility, that the $\mathrm{Na}^{+}$ conductances of the two sets of vesicles were different and that this generated a difference in vesicle membrane potential driving electrogenic MeAIB uptake, can probably be discounted because there was no significant difference between the two groups in terms of the (most likely diffusional) amiloride-insensitive $\mathrm{Na}^{+}$ uptake.

A potentially important observation was that the initial rate of MeAIB uptake by the $\mathrm{Na}^{+}$-independent route was also lower in the SGA vesicles. This route probably has two components, a diffusional (nonsaturable) component and a transport proteinmediated (saturable) component. Our current data do not allow 
us to separate these, but it seems most likely that it is the latter that is different in SGA vesicles. This is based partly on the observation that diffusional (amiloride-insensitive) $\mathrm{Na}^{+}$uptake is unaltered and partly on the cordocentesis data, which show that the concentration of a wide range of amino acids is lower in umbilical vein plasma of SGA compared with AGA babies (9). suggesting the involvement of a variety of amino acid transporters. Clearly, the nature and activity of $\mathrm{Na}^{+}$-independent MeAIB uptake as well as that of other amino acid transporters in SGA, compared with $A G A$, vesicles requires further investigation.

The absence of any significant difference in the initial rate of $\mathrm{Na}^{+}$transport due to the $\mathrm{Na}^{+} / \mathrm{H}^{+}$exchanger or the amilorideinsensitive $\mathrm{Na}^{+}$uptake between the $\mathrm{AGA}$ and $\mathrm{SGA}$ vesicles suggests that the difference in the system A amino acid transporter is not due to a generalized membrane transport defect, but rather to a specific change in amino acid handling. One possible explanation for the altered transporter behavior in SGA vesicles could relate to the difference in lipid content between placentas from SGA and AGA babies (31). This could affect membrane fluidity and both carrier-mediated and non-carriermediated transport of substrates, although from the present study amino acid transport would have to be particularly susceptible to this.

This study was stimulated by a report that total, i.e. carriermediated plus diffusional, AIB uptake is lower in SGA compared with $A G A$ vesicles (13). The data presented here are an important confirmation and extension of this earlier study because they demonstrate the following: $I$ ) There is no difference in purity between isolated SGA and AGA vesicles (enrichment ratios are not different); 2) the lower amino acid uptake in the SGA vesicles is not due to a generalized defect affecting all transport proteins $\left(\mathrm{Na}^{+} / \mathrm{H}^{+}\right.$exchanger activity not different between $\mathrm{SGA}$ and $\mathrm{AGA}$ groups): and 3) a reduced system $A$ amino acid transporter activity (confirmed by using MeAIB and by demonstrating a difference in the $\mathrm{Na}^{+}$-dependent uptake) as well as a reduced $\mathrm{Na}^{+}$-independent MeAIB uptake is responsible for the lower total MeAlB uptake, with the difference in the former being due to an effect on the $V_{\max }$ of the carrier.

As discussed above, further studies are required to determine whether other amino acid transporters in both microvillous and basal membranes of the syncytiotrophoblast are abnormal in placentas from SGA babies and, furthermore, whether defects such as that observed for the system $A$ transporter play an etiologic role in intrauterine growth retardation.

Acknowledgme'nt. The authors thank the staff of the Central Delivery Unit of St. Mary's Hospital, Manchester, for their assistance in this project.

\section{REFERENCES}

1. Burke G. Stuart B. Crowley P. Scanaill S.N, Drumm J 1990 Is intrauterine growth retardation with normal umbilical antery blood flow a benign condition? Br Med J 300:1044-1045

2. Jones RAK, Robertson NRC 1984 Problems of the small for dates baby. Clin Obstet Gynecol 11:499-524

3. D'Souza SWD 1988 Outcome of modern intensive care for low hirthweight infunts. Midwives Health Visitors Community Nurse 24:484-488

4. James D 1990 Diagnosis and management of fetal growth retardation. Arch Dis Child 65:390-394
5. Barker DJP, Bull AR, Osmond C, Simmonds SJ 1990) Fetal and placental size and risk of hypertension in adult life. Br Med J 301:259-262

6. Owens JA. Owens PC. Robinson JS 1989 Experimental fetal growth retardation: metabolic and endocrine aspects. In: Gluckman PD, Johnson BM Nathaniclsz. PW (eds) Advances in Fetal Physiology. Perinatology Press. lihaca, NY, pp 263-286

7. Nitzan M. Orloff S. Schulman JD 1979 Placental transfer of analogues of glucose and amino acids in experimental intrauterine growth retardation. Pediatr Res 13:100-103

8. Jansson T. Persson E 1990 Placental transfer of glucose and amino acids in intrauterine growth retardation: studies with substrate analogues in the awake guinea pig. Pediatr Res 28:203-208

9. Cetin I, Corbetta C, Sereni LP. Marconi AM, Bozzetti P. Pardi G. Battaglia FC 1990 Umbilical amino acid concentrations in normal and growth retarded fetuses sampled in utero by cordocentesis. Am J Obstet Gyneco 162:253-261

10. Bernardini I, Evans M1I, Nicolaides KH Economides DL Gihl WA 1991 The fetal concentrating index as a gestational age-independent measure of placental dysfunction in intrauterine growth retardation. Am J Obstet Gyneco $164: 1481-1490$

11. Rosso P 1975 Maternal malnutrition and placental transfer of $\alpha$ aminoisobutwric acid in the rat. Science 187:648-649

12. Varma DR. Ramakrishnan R 1990 Effects of protein caloric malnutrition on transplacental kinetics of aminoisobutyric acid in rats. Placenta 12:277-28

13. Dicke JM. Henderson GI 1988 Placental amino acid uptake in normal and complicated pregnancies. Am J Med Sci 295:223-227

14. Johnson L.W, Smith CH 1988 Neutral amino acid transpon systems of microvillous membrane of human placenta. Am J Physiol 254:C773-C780

15. Balkovetz. DF. Leibach FH, Mahesh VB, Devoc LD. Cragoe EJ Jr, Ganapathy V $1986 \mathrm{Na}^{+}-\mathrm{H}^{+}$exchanger of human placental brush border membrane: identification and characterization. Am J Physiol 251:C852-C860)

16. Gairdner D. Pearson J 1971 A growth chart for premature and other infants Arch Dis Child 46:783-787

17. Glazier JD, Jones CJP. Sibley CP 1988 Purification and $\mathrm{Na}^{+}$uptake by human placental microvillous membrane vesicles prepared by three different methods. Biochim Biophys Acta 945:127-134

18. L.owry OIf. Rosebrough NJ, Farr AL. Randall RJ 1951 Protein measuremen with the Folin phenol reagent. J Biol Chem 193:265-275

19. MAComb RB. Bowers GN 1972 Study of optimum buffer conditions for measuring alkaline phosphatase activity in human serum. Clin Chem 18:97104

20. Sottocasa GL. Kuylenstierna B, Ernster L. Bergstand A 1967 An electron transport system associated with the outer membrane of liver mitochondria. A biochemical and morphological study. J Cell Biol 32:415-438

21. Feischer S. Brierley G, Klouwen H, Slautterback DB 1962 Studies of the electron transfer system XLVII. The role of phospholipids in electron transfer. J Biol Chem 237:3264-3272

22. Benos DJ 1982 Amiloride: a molecular probe of sodium transport in tissues and cells. Am J Physiol 242:C131-C145

23. Gasko OD. Knowles AF, Shertzer HG. Suolinna E-M, Racker E 1976 The use of ion exchange resin for studying ion transport in biological systems. Anal Biochem 72:57-65

24. Christensen HN 1985 On the strategy of kinetic discrimination of amino acid transport systems. J Membr Biol 84:97-103

25. Kudo Y, Boyd CAR 1990 Characterisation of amino acid transport systems in human placental basal membrane vesicles. Biochim Biophys Acta 1021:169174

26. Hoeltzli SD. Smith CM 1989 Alanine transport systems in isolated basal plasma membrane of human placenta. Am J Physiol 256:C630-C637

27. Miyamoto Y. Balkovetz DF. Leibach FH. Mahesh VB. Gananathy V 1988 $\mathrm{Na}^{+}$and $\mathrm{Cl}^{-}$gradient driven high affinity uphill transport of taurine in human placental brush border membrane vesicles. FEBS Lett 231:26.3-267

28. Karl PI. Tkaczerski H. Fisher SE 1989 Characteristics of histidine uptake of human placental microvillous membrane vesicles. Pediatr Res 25:19-26

29. Kudo Y', Boyd CAR 1990 Human placental t.-tyrosine transport: a comparison of brush border and hasal membrane vesicles. J Physiol 426:381-395

30. Karl PI, Teichberg S, Fisher SE $1991 \mathrm{Na}^{+}$dependent amino acid uptake by human placental microvillous membrane vesicles: importance of storage conditions and preservation of cytoskeleton elements. Placenta 12:239-250

31. Percy P. Vilhergsson G, Percy A, Mansson JE. Wennergren M. Svennerholm $\mathrm{L} 1991$ The fatty acid composition of placenta in intrauterine grouth retardation. Biochim Biophys Acta 1084:173-177 